\title{
Becoming WISE about the Environment: A Novel Approach to an Overnight Summer Science Camp for Young Females
}

\author{
Michael Bindis ${ }^{1 \star}$, Christa Currie $^{1}$
}

\author{
${ }^{1}$ Mount St. Joseph University, UNITED STATES \\ *Corresponding Author: michael.bindis@msj.edu
}

Citation: Bindis, M., \& Currie, C. (2021). Becoming WISE about the environment: A novel approach to an overnight summer science camp for young females. Interdisciplinary Journal of Environmental and Science Education, 17(2), e2233. https://doi.org/ 10.21601/ijese/9331

\begin{abstract}
ARTICLE INFO
ABSTRACT

Received:

25 August 2020

In order to encourage female students to pursue science as a career, an overnight science camp known as the Women in Science Experience (WISE) was developed and implemented at Mount St. Joseph University. The camp was developed for girls who were 14-17 years of age as a residential experience to simulate life on

Accepted:

3 September 2020 a university campus. This manuscript describes the implementation of the camp, including development of content and organization of the camp schedule. The camp was evaluated by student participants using a survey that contained Likert-style and open response questions, with students reporting overall satisfaction with the camp. The manuscript discusses the student responses to the survey and describes the lessons learned from the entire process of developing and running WISE.
\end{abstract}

Keywords: informal science education, secondary education, gender and STEM

\section{INTRODUCTION}

There is a need to increase the number of women who seek a career in science. Recent figures show that women in the United States in 2016 received just 39\% of doctoral degrees in chemistry, $19 \%$ in physics, and $24 \%$ in engineering (National Center for Science and Engineering Statistics, 2019). One possible reason for this is that the likelihood of a female graduating from a doctoral program decreases when there are no other females in the program (Bostwick \& Weinberg, 2018). Motivating female students to become scientists has also been a challenge. A 2017 survey conducted among 11,000 girls in Europe concluded that, while interest in science, technology, engineering, and mathematics (STEM) begins around the age of 11 or 12, that interest wanes once the girls become 14 or 15 (Microsoft Philanthropies, 2017).

One way to address these issues is to create and implement informal science education programs that can occur during the school year (Kant, Burckhard, \& Meyers, 2018) or in the summer (Bryant Davis \& Hardin, 2013; King \& Pringle, 2019). These programs must be able to involve students in hands-on learning experiences, respond to students' interests in STEM, and connect the learning of STEM inside and outside of the classroom (National Research Council, 2015). We have developed one such program, described in this manuscript, to encourage females to pursue science careers. The Women in Science Experience (WISE) is a residential summer camp that allows young women, ages 14 to 17 , to participate in an immersion experience, involving experimentation concerning water quality both off campus and on campus, which leads to a public presentation at conclusion of the camp. Because WISE is an immersion experience, WISE participants live on campus to simulate what it is like to participate in postsecondary education. Another opportunity for WISE participants was to meet with women who are in science careers outside of academia. We decided to include this because we wanted WISE participants to learn of the many possibilities that one can have when obtaining a university degree in science. As a result of these combined efforts, WISE is a novel way for students to gain scientific knowledge, learn about science careers, interact with female scientists who work in a variety of fields, and live in a campus setting. Results from WISE student evaluations demonstrate widespread engagement in camp activities, satisfaction with the 
camp and its potential to positively impact the future of women in science, and areas for improvement to make WISE better in future iterations of the camp.

\section{STEM CAMPS FOR FEMALES}

Programs exclusively for females have been done in prior years. One such program was held at Florida Gulf Coast University. The program was known as Girls in Engineering, Math, and Science (GEMS), which was run by female scientists and included undergraduate and graduate students who served as teaching assistants. GEMS consisted of a series of workshops held on Saturday mornings for female students who were of ages 12 to 14 (Dubetz \& Wilson, 2013). The University of Central Florida was another location for a STEM program for females, which especially reached out to students who were between the ages of 10 to 14 and came from low-income backgrounds. This program had students come to campus for one of seven two-day camps that looked at STEM as seen by university and industry personnel (Bryant Davis \& Hardin, 2013).

A program at South Dakota State University (SDSU) engaged Native American female students in STEAM (science, technology, engineering, art, mathematics) in a program known as STEAM Girls. This program consisted of a series of bus trips to SDSU throughout the school year with activities that promoted STEM but also were made relevant to Native American culture (Kant, Burckhard, \& Meyers, 2018). Another program developed by a high school in Massachusetts was a week-long day camp that immersed middle school girls aged 12 to 14 in STEM concepts. The purpose of the camp was to have tiered mentoring in STEM from female scientists to high school students, who would then mentor the middle school females (Emeagwali, 2016).

While all of these camps provide excellent opportunities for girls to learn about STEM, they do not look at the possibilities that can occur at the university level outside of the laboratory or classroom. Students at these camps are only on a university campus or other location during the daytime. As a result, these students are missing out on the opportunity to experience all aspects of life on a university campus, including social activities and living in on-campus housing. This is where WISE is set apart from other STEM camps, in that the WISE campers had an immersion experience in a university. Thus, WISE students were able to live on campus, eat in campus dining halls, use recreational facilities, and participate in group bonding activities that are similar to residence hall programs for undergraduate students. Having students live on campus during WISE opened up more opportunities for students who wanted to learn not just science but also learn about all of the ways to participate in a university setting outside of classroom and laboratories. These social experiences were just as valuable for the WISE campers as were the lab experiments and STEM education.

\section{METHODS}

\section{Developing Content}

The WISE program was developed at Mount St. Joseph University, a small, private university in Cincinnati, Ohio, USA. We decided it was important to have a substantive, hands-on component to allow WISE participants to engage directly in science, as this is critical to a successful informal science experience (National Research Council, 2015). As a result, we decided to focus on experimentation concerning water quality, both because of the expertise of the faculty involved in the camp and also based upon teaching content that is normally not offered in secondary schools. Students participated in activities that included a mix of field-based and laboratory-based experiments. The field-based experience required travel to an off-site water stream in a nearby park to conduct the experiments. Students worked in small groups of two or three on all experiments.

The first set of experiments required students to examine the health of the stream by looking for the presence or absence of invertebrate animals. Students were asked to enter the shallow stream and count the number of animals present in a one-hour period, ranked according to different levels of taxa as found in a government-developed publication at the state level that allows average citizens to study and determine the health of a water stream (Ohio Department of Natural Resources, 1993). Data from the small groups were combined to obtain an overall assessment score of the health according to aquatic life. Next, students worked in their small groups and used a water testing kit (LaMotte Company, 2018) which tested for nitrates, dissolved oxygen, turbidity, bacteria, $\mathrm{pH}$, and temperature. Students then collected water samples from the stream to complete additional testing on campus. All of the activities at the stream were led by a female faculty member who studied the stream in her environmental science classes that she taught at the undergraduate level. This meant that WISE students were performing the same experiments that were done by university students.

Returning to campus, one of us (Currie) oversaw the explanation of experiments to be done in the laboratory, while the other of us (Bindis) assisted students with experiments as needed. One added aspect of on-campus experiments was that the students selected a second water sample, choosing a water sample that came from a different source, including other natural streams, 
seawater, tap water, and swimming pools. Students evaluated the second set of water samples using the same water testing kit used on the stream on site. Then, the students tested all water samples using a mix of wet and instrumental experiments in the chemistry laboratory. The specific experiments varied slightly from year to year. Wet chemistry experiments included total suspended solids, total dissolved solids, alkalinity, and buffer capacity, while instrumental experiments have involved atomic absorption spectroscopy (Smith, 1983). Content was presented in a way that students of various levels and abilities were able to comprehend content, the laboratory apparatus, and other equipment being used.

In short, students performed a wide variety of experiments in order to answer multiple scientifically relevant questions. The goal of having such an extensive activity was to expose students to a number of different applications of the scientific method and the need to gather a range of evidence when conducting scientific evaluation. This also allowed connections to STEM to be seen both in and out of the classroom, another key component of a quality informal science education program (National Research Council, 2015).

\section{Recruiting Students}

Students were recruited to participate in WISE in a variety of ways. In order to participate in WISE, students who were going to be in grades 9 through 12 the following school year were allowed to participate, with ages ranging from 14 to 17. Local Educational Service Centers (ESC) helped with promotion of WISE on their website and with collecting registration information of WISE camp participants. A recruiting flyer was created within the School of Education and was sent to the School of Behavioral and Natural Science, which had an electronic mailing list of science teachers in the region. Emails were sent with the attached flyer to science teachers in the region's high schools. Flyers were also taken by staff members from the MSJ Admissions department when they visited area high schools. These area high schools included both public and private schools in the region. Science teachers would then recommend students for the camp in order to qualify for scholarships to attend WISE. Actual participants came from a mix of private schools, public schools, and home schooling.

\section{Operation of WISE}

The WISE camp was originally developed to last over five days, but dropped to four days after the first year (Table 1). We will address this later in the article. Both of us served as co-directors of WISE and ran all daytime activities. On the night before field work and laboratory experiments began, students checked in to campus housing. This allowed students to become familiar with the campus and with peers. A Resident Director, who was a member of the university's Admissions department, supervised WISE students in the evenings with support from two resident assistants who were students of the university. Daytime activities led by us as co-directors revolved around laboratory experiments, while evening activities revolved around career exploration and social time. The final portion of the camp focused on presentations of findings before camp personnel and peers. Students were asked to reference standards of water quality, including those given by the Environmental Protection Agency (2019). Parents, teachers, and family were invited to the presentation held in the evening of Day 4 of the camp.

\section{Evaluation of WISE}

On the final day of the camp, students completed a survey about their experience during WISE. The survey was approved by the university's Institutional Review Board prior to being administered to students. Parents signed an informed consent form as a part of the registration process, and students gave written assent on a form separate from the survey. This was done to preserve anonymity of the students and to allow students to be as honest as possible when responding to the survey. Students' names were not collected, and pseudonyms were assigned to each student's responses. Students responded about different facets of the camp, including laboratory planning, social time, dorms, food, career activities, etc. The survey consisted of two parts: a set of Likert-style items, using a five-point scale with room to provide open-ended feedback on any aspect of the camp, and a series of six open-ended questions. After the list of items in part one of the survey, students were given the following direction to provide additional feedback: "General Comments on any of the above (or anything else related to WISE)." Refer to the Appendix for the layout and design of both parts of the survey. The general comments were used to support the findings from the Likert-style items and to help with improvements of operating WISE.

Originally, 14 Likert-style items were used, but this was pared back to 12 items as the camp developed. The eliminated items were based on events held on Day 5 of the camp but were no longer offered when the camp was changed to a 4-day camp. The second part of the survey consisted of a set of six open-ended questions which asked students to discuss their opinions about science, careers in science, and how WISE affected their opinions about science and careers in science. The goal of the openended questions was to examine student perceptions of 
Table 1. Daily Activities in WISE

\begin{tabular}{|c|c|c|c|}
\hline & Morning & Afternoon & Evening \\
\hline Day 1 & & & $\begin{array}{l}\text { Check into dorm room } \\
\text { Meet WISE staff } \\
\text { Icebreaker activities }\end{array}$ \\
\hline Day 2 & $\begin{array}{l}\text { Travel to water stream Con- } \\
\text { duct invertebrate and water } \\
\text { quality experiments }\end{array}$ & $\begin{array}{l}\text { Complete experiments } \\
\text { Gather water samples } \\
\text { Return to campus } \\
\text { Lab safety presentation } \\
\text { Laboratory experiments }\end{array}$ & $\begin{array}{l}\text { Online call with female professor in Alaska } \\
\text { Recreational activities }\end{array}$ \\
\hline Day 3 & $\begin{array}{l}\text { Laboratory experiments } \\
\text { Analyze data }\end{array}$ & $\begin{array}{l}\text { Laboratory experiments } \\
\text { Analyze data } \\
\text { Work on presentations }\end{array}$ & $\begin{array}{l}\text { Panel discussion with women in science careers } \\
\text { Recreational activities }\end{array}$ \\
\hline Day $4^{\mathrm{a}}$ & $\begin{array}{l}\text { Complete laboratory exper- } \\
\text { iments } \\
\text { Work on presentations }\end{array}$ & $\begin{array}{l}\text { Complete presentations } \\
\text { Rehearse presentations } \\
\text { Check out of dorm room }\end{array}$ & Dinner and presentations \\
\hline
\end{tabular}

${ }^{a}$ Camp lasted five days in first year that WISE operated. Checkout of dorm rooms and final presentations occurred on Day 5

science, science careers, and their own efforts for future education. The overall goal of the survey was to gauge effectiveness, value, and satisfaction with the camp. For the purposes of this article, the data presented will come from the Likert-style questions and from comments wrote at the bottom of the first part of the survey. A thorough and detailed analysis of the six open-ended questions from the second part of the survey has been published elsewhere by one of us (Bindis, 2020).

\section{Analysis of Likert-style Questions}

Analysis of the data depicted in Table 2 revealed mostly positive feedback about WISE for the high school participants. Mean scores in any individual year ranged from 3.75 to 5.00 , while cumulative means ranged from 4.00 to 4.86. Confidence intervals for each cumulative mean were small, ranging from as low as 0.11 to as high as 0.29 . This indicated that the features of the camp addressed in the survey met or exceeded the expectations of the students.

The ratings with the highest values over the course of offering WISE were for staff members (4.86), followed by their overall impression of WISE (4.74) and recreation time (4.71). Lowest overall ratings were for science lab instruction, including lab testing (4.05) and research (4.00), although students appeared to enjoy the onsite collection and testing of data at the water stream (4.47). Even though students had some suggestions for improvements on laboratory work, the overall score on laboratory-related work on a five-point scale indicated above-average satisfaction with experiments on the part of students. Some of the students were unfamiliar with some of the lab apparatus being used on campus, which included vacuum filtration for the total suspended solids experiment and burets for the alkalinity and buffer capacity experiments. The students did not appear to be as enthusiastic about experiments on campus as they were with the experiments done at the water stream, although the ratings given by the students were in the above-average range or higher. Student interest in the off-campus experiments allowed students to see STEM in action outside of a classroom or laboratory setting, an important feature of informal science programs as stated by the National Research Council (2015).

A valuable aspect of the questionnaires is that they allowed WISE organizers to make adjustments to improve the program over time. Integrating changes in response to feedback is critical in the future development of camps intended to improve outcomes for women in science. One change that was made after the first year of WISE was to improve the opening night activities, including where to arrive on campus on the first night. In particular, there were two students from the first year who asked that improvements needed to be done for the first night (Alice and Bernice), and this was made further apparent by the opening night activities receiving the lowest mean rating in 2014. Organizers decided to make the opening night activities for the 2015 camp to be more formal than they were in 2014. Survey results showed that this was a good decision, as the mean rating for opening night activities improved by almost a full point ( 3.75 vs. 4.73 ). The difference in means for 2014 and 2015 was proven to be statistically significant by a t-test $(t=-4.737, p=0.001)$. Thus, the improvements in the opening night activities from 2014 to 2015 were important to making WISE camp successful. 
Table 2. Mean scores for Likert-style questions, WISE Survey ${ }^{\mathrm{a}}$

\begin{tabular}{|c|c|c|c|c|c|}
\hline Feature/activity & $\begin{array}{l}2014 \\
(n=8) \\
\end{array}$ & $\begin{array}{l}2015 \\
(n=11)\end{array}$ & $\begin{array}{l}2016 \\
(n=10)\end{array}$ & $\begin{array}{l}2017 \\
(n=9)\end{array}$ & $\begin{array}{l}\text { Cumulative }^{\mathrm{b}} \\
(\mathrm{n}=38)\end{array}$ \\
\hline Opening Night Activities & 3.75 & 4.73 & 4.10 & 4.22 & $4.24 \pm 0.26$ \\
\hline Trip to Park (Sample Collection) & 4.75 & 4.27 & 4.00 & 5.00 & $4.47 \pm 0.19$ \\
\hline Science Lab Instruction: Lab Testing & 4.25 & 4.00 & 3.90 & 4.11 & $4.05 \pm 0.29$ \\
\hline Science Lab Instruction: Research & 4.25 & 4.09 & 3.80 & 3.89 & $4.00 \pm 0.26$ \\
\hline Panel Presentation & 5.00 & 4.45 & 4.10 & 3.89 & $4.34 \pm 0.29$ \\
\hline College Prep Time & 3.86 & 4.36 & 4.10 & 4.56 & $4.24 \pm 0.24$ \\
\hline Online Talk (Research Scientist) & 4.43 & 4.64 & 3.80 & 4.22 & $4.27 \pm 0.28$ \\
\hline Meals & 4.56 & 4.09 & 3.90 & 4.67 & $4.28 \pm 0.24$ \\
\hline Staying in Dorms & 4.50 & 4.36 & 3.90 & 4.33 & $4.26 \pm 0.27$ \\
\hline Evening activities (recreation time) & 4.50 & 4.45 & 4.90 & 5.00 & $4.71 \pm 0.16$ \\
\hline Staff Members & 4.63 & 5.00 & 4.75 & 5.00 & $4.86 \pm 0.11$ \\
\hline Overall Impression of WISE & 4.63 & 4.73 & 4.60 & 5.00 & $4.74 \pm 0.16$ \\
\hline
\end{tabular}

${ }^{\mathrm{a}} 1$ = poor, 2 = below average, 3 = average, 4 = above average, $5=$ excellent

${ }^{b}$ Mean of all data combined, with 95\% confidence intervals for each combined mean

\section{Analysis of General Comments}

The general comments provided by the students at the end of Part One of the survey were analysed for common themes. From the analysis of the general comments, two themes emerged: positive feedback and improvements needed for WISE. Some sample comments of student feedback that was positive are included in Table 3. Some positive feedback was simple, such as Francine in 2017: "I had a great time." Another simple comment was made by Gina in 2016, who stated, "I had tons of fun." Other students liked the science that was studied, including Olive from 2015: "LOVED it! Wished it could be a little longer and a little more diverse in the science, but the science was still great!"

The second theme of the general comments had to do with ways to improve WISE in the future. Some of the comments of students that fit the theme of improvement are provided in Table 4. There were the comments of Alice and Bernice from the first year of WISE, as previously described, about directions to opening night activities, which was a major correction made for the second time that WISE was offered. Gladys commented on both the science part of the camp and dorm life when she said, "I wasn't quite sure what our presentations were supposed to be about. The rooms and dining hall were a little cold." This comment led to some improvements in being more explicit about presentations and offering more support to the students before they gave their presentations at the end of the camp. Some students gave both positive feedback and ways to improve the camp. This can be seen in Shelly's comments that are depicted in Table 3, where she gives positive feedback about the staff members but wanted to do more outdoor activities like those done on Day 2 of the camp. Another person who gave both positive and improvement feedback was Irene from 2015, who said, "I think that we shouldn't have a curfew. I did like the experience." All of the feedback provided by the WISE students were taken into account for each subsequent year that the camp was offered.

\section{CONCLUSIONS}

As stated above, modifications to WISE were made annually in order to maintain successful implementation. Each year, camp personnel met soon after the conclusion of the camp to review issues related to logistics and activities that were being offered. These meetings included us as the co-directors, administrative assistants, deans, and Admissions department representatives. One of the co-directors (Bindis) also met with the ESC partners to evaluate the camp, with the ESC creating annual reports that shared WISE with the general public. In addition, data from student surveys helped with changes in activities, including variation of laboratory activities and improvements to the career panel featuring women scientists. Simultaneously, many things proved to be useful for future iterations of the camp, such as the trip to a nearby stream, having recreational time in the evenings, and providing an immersion experience that students 


\begin{tabular}{lll}
\hline \multicolumn{2}{l}{ Table 3. Comments from Students: Positive Feedback } \\
\hline Student & Year & Comment \\
\hline Delilah & 2017 & $\begin{array}{l}\text { All of the speakers/people we met were happy to help us + talk to us about new informa- } \\
\text { tion and to have pleasant conversations, which was wonderful. }\end{array}$ \\
Delores & 2014 & $\begin{array}{l}\text { Staff exceeded chart they were above awesome!! The panel was really nice. } \\
\text { Lola }\end{array}$ \\
& 2016 & All Staff members were really nice and helpful! \\
Shelly & $\begin{array}{l}\text { I really like talking to the staff members and getting more info about my future. And I think } \\
\text { we should spend more time outside. } \\
\text { I loved the camp. Wish we would have done more experiments outside of the box, like } \\
\text { explosions and bubbles and stuff. But I loved the camp overall. }\end{array}$ \\
\hline
\end{tabular}

a Pseudonyms

Table 4. Comments from Students: Improvements needed for WISE

\begin{tabular}{|c|c|c|}
\hline Student ${ }^{\mathrm{a}}$ & Year & Comment \\
\hline Alice & 2014 & $\begin{array}{l}\text { I would make the directions on how to get here more specific because they were rather } \\
\text { confusing }\end{array}$ \\
\hline Bernice & 2014 & I think directions on where to first arrive would be helpful. \\
\hline Janet & 2015 & I would like to do more outside activities. \\
\hline Nancy & 2015 & $\begin{array}{l}\text { Maybe a different type of science. More medical field stuff - Nursing? Lab felt very repeti- } \\
\text { tive. A lot of water work? }\end{array}$ \\
\hline Kerry & 2016 & Breakfast was bad but other food was good! \\
\hline Ethel & 2017 & $\begin{array}{l}\text { Have staff knock on door loud to make sure that people are up; put more information } \\
\text { about camp online }\end{array}$ \\
\hline
\end{tabular}

aPseudonyms

enjoy during their time at WISE.

The planning, organization, and implementation of WISE offered a number of different learning opportunities for the faculty and staff of the university. One aspect was developing, fostering, and maintaining relationships among various parts of the university. These relationships came from both academic and non-academic departments, allowing for the camp to continue as an immersion experience. External relationships were also beneficial, as WISE was developed in partnership with county-level ESC. We recommend that meetings are held throughout the year among all partners, so that all logistics and issues related to the camp can be addressed before students come to campus and to ensure that all partners are working cooperatively. Issues related to funding must be addressed early in the process to avoid possible cancellation of the camp, especially when external funding is desired from grant funding agencies. Grant funding was available for two of the years in which WISE operated (2015 and 2016), but additional financial support was available each year from the ESC.

If you want students to have an immersion experience such as WISE, it is important to balance science-related activities and other features of the camp for the students. Students need adequate breaks throughout the day to avoid fatigue that develops as the camp progresses. Our experience was that students developed fatigue as soon as the second full day of the camp, and it was decided that breaks needed to be longer and more frequent than originally planned. Thus, it is important to be flexible in scheduling activities during the day and in the evening. Because of the fatigue of the campers, we decided to pare 
down the camp from 5 days to 4 days. It was also decided to end the camp after 4 days so that parents could attend presentations in the evening of Day 4 and not at lunch time on Day 5, which was done in the first iteration of the camp in 2014. In addition, we wanted to invite science teachers, principals, and university administrators to view the presentations, and it was easier to have the presentations in the evening of Day 4. Finally, it is important to have a variety of science experiments related to water quality in order to avoid staleness of the camp offering after each year. Working in the field in a stream early in the camp may make laboratory work completed on campus later in the week seem to be less exciting, as indicated by the mean scores on the end-of-camp survey.

\section{LIMITATIONS}

While much has been learned from operation of WISE and from student feedback, caution must be taken with the results from the Likert-style questions. The survey was administered only once, meaning that the results reflect student opinions at the time the survey was completed and does not reflect possible changes in opinions beyond the time of the camp. There was no follow-up data collection from WISE participants after the camp was concluded. It is also possible that the student responses resulted from a novelty effect, meaning that student responses may have resulted from WISE being a new and different experience for the students. The novelty effect is also possible since the camp lasted less than one week. Having a novelty effect could address the favourable responses provided by camp participants. Also, the sample size each year was small, with as few as eight participants to as many as eleven participants. It should also be noted that students only attended one year and did not come back for a second time to WISE. This was done, in part, because we were unable to provide advanced activities for returning campers. We suggest that you include advanced activities in order for students to attend more than one year.

\section{IMPLICATIONS}

Overall, WISE is a unique learning opportunity for high school females in a residential setting on a university campus. The immersion experience of WISE can spur interest in science, science careers, and higher education. Students can benefit from learning from successful women in science careers and develop or strengthen knowledge in science and scientific skills. Partnerships between organizations both on-campus and off-campus can keep a summer camp such as WISE successful and sustainable for many years. Connecting content to learning standards is also important, so that parents of participants understand that learning was taking place during the camp. Future iterations of WISE may have a theme different than water quality, which would allow students to participate on multiple occasions without repetition, which is valuable because it could provide valuable data that allows us to observe whether interest in science among participants grows year-over-year. Also, to address the limitations of the data presented, follow-up interviews or surveys should be administered to examine long-term effects of participation in the summer camp. Possible areas of study would be changes in student opinions over time, persistence in science in secondary school and beyond, and ways to address environmental quality.

\section{ACKNOWLEDGMENTS}

The authors would like to thank the Farmer Family Foundation and the Duke Energy Foundation for financial support of WISE. The authors would also like to thank the Butler County and Warren County Educational Service Centers for marketing and financial support.

\section{REFERENCES}

Bindis, M. (2020). Opinions of secondary school females toward science and science careers. International Journal of Science and Mathematics Education. 18, 1655-1671.

Bryant Davis, K., \& Hardin, S. (2013). Making STEM fun: How to organize a STEM camp. Teaching Exceptional Children, 45(4), 60-67.

Dubetz, T., \&Wilson, J. (2013). Girls in engineering, mathematics, and science, GEMS: A science outreach program for middleschool female students. Journal of STEM Education, 14(3), 41-47.

Emeagwali, N. S. (2016). Women in STEM: Their evolution, triumphs and challenges. Techniques: Connecting Education \& Careers, 91(8), 14-19.

Environmental Protection Agency (2019). Water quality standards: Regulations and resources. Retrieved from https://www.epa.gov/wqs-tech

Kant, J., Burckhard, S., \& Meyers, R. (2018). Engaging high school girls in Native American culturally responsive STEAM enrichment activities. Journal of STEM Education, 18(5), 1525.

King, N., \& Pringle, R. (2019). Black girls speak STEM: Counterstories of informal and formal learning experiences. Journal of Research in Science Teaching, 56(6), 539-569.

LaMotte Company (2018). Earth Force Low Cost Water Monitoring Kit. Chestertown, MD.

Microsoft Philanthropies. (2017). Why Europe's girls aren't studying STEM. Retrieved from https://onedrive.live.com/ view. aspx?cid=089f9bc9ce672ff4\&id=documents\&resid $=89$ F9B C9CE672FF4 $108 \&$ app $=$ WordPdf\&authkey $=$ ANKQohgdrHsqJg\&

National Center for Science and Engineering Statistics (2019). Women, Minorities, and Persons With Disabilities in Science and Engineering. Arlington, VA: National Science Foundation.

National Research Council (2015). Identifying and Supporting 
Productive STEM Program in Out-of-School Settings. Washington, D.C.: National Academies Press.

Ohio Department of Natural Resources (1993). A guide to volunteer stream quality monitoring. Columbus, $\mathrm{OH}$ : Division of Natural Areas and Preserves, Ohio Department of Natural Resources:

Smith, R. (1983). A Laboratory Manual for the Determination of Metals in Water and Wastewater by Atomic Absorption Spectroscopy; Pretoria, South Africa: National Institute for Water Research, Council for Scientific and Industrial Research. Accessed from: https://inis.iaea.org/collection/ NCLCollectionStore/_Public/15/030/15030051.pdf 


\section{APPENDIX}

\section{WISE Survey}

General Directions: Thank you for participating in WISE! We would like for you to take no more than 30 minutes to complete the following survey. Your feedback is greatly appreciated.

DO NOT write your name or any other information that may identify you. We wish your responses to remain anonymous.

Part One. Answer the following questions by circling the appropriate number $(1=$ poor, $2=$ below average, $3=$ average, $4=$ above average, $5=$ excellent, $\mathrm{N} / \mathrm{A}=$ not applicable/unsure)

\begin{tabular}{|c|c|c|c|c|c|c|}
\hline Opening night activities & 1 & 2 & 3 & 4 & 5 & $\mathrm{~N} / \mathrm{A}$ \\
\hline $\begin{array}{l}\text { Trip to Miami Whitewater Park } \\
\text { (Sample collection) }\end{array}$ & 1 & 2 & 3 & 4 & 5 & $\mathrm{~N} / \mathrm{A}$ \\
\hline Science Instruction Time: Lab Testing & 1 & 2 & 3 & 4 & 5 & $\mathrm{~N} / \mathrm{A}$ \\
\hline Science Instruction Time: Research & 1 & 2 & 3 & 4 & 5 & $\mathrm{~N} / \mathrm{A}$ \\
\hline Panel Presentation: Women in Science & 1 & 2 & 3 & 4 & 5 & $\mathrm{~N} / \mathrm{A}$ \\
\hline College Prep Time & 1 & 2 & 3 & 4 & 5 & $\mathrm{~N} / \mathrm{A}$ \\
\hline Skype Talk & 1 & 2 & 3 & 4 & 5 & $\mathrm{~N} / \mathrm{A}$ \\
\hline Meals & 1 & 2 & 3 & 4 & 5 & $\mathrm{~N} / \mathrm{A}$ \\
\hline Staying in dorms & 1 & 2 & 3 & 4 & 5 & $\mathrm{~N} / \mathrm{A}$ \\
\hline Evening activities (recreation time) & 1 & 2 & 3 & 4 & 5 & $\mathrm{~N} / \mathrm{A}$ \\
\hline Staff members & 1 & 2 & 3 & 4 & 5 & $\mathrm{~N} / \mathrm{A}$ \\
\hline Overall impression of WISE & 1 & 2 & 3 & 4 & 5 & $\mathrm{~N} / \mathrm{A}$ \\
\hline
\end{tabular}

General Comments on any of the above (or anything else related to WISE):

Part Two. Answer the following questions based on your experiences.

1. What motivated you to attend WISE?

2. Were you interested in science as a career prior to attending WISE? Why or why not?

3. Has attending WISE affected your career decisions? Why or why not?

4. What is your opinion about pursuing a career in science?

5. Has attending WISE made an effect on your opinions about science careers? Explain.

6. What are your future plans for furthering your education? 